\title{
Cerebellar-Dependent Expression of Motor Learning during Eyeblink Conditioning in Head-Fixed Mice
}

\author{
(1) Shane A. Heiney, Margot P. Wohl, @Selmaan N. Chettih, Luis I. Ruffolo, and Javier F. Medina \\ Psychology Department, University of Pennsylvania, Philadelphia, Pennsylvania 19104
}

Eyeblink conditioning in restrained rabbits has served as an excellent model of cerebellar-dependent motor learning for many decades. In mice, the role of the cerebellum in eyeblink conditioning is less clear and remains controversial, partly because learning appears to engage fear-related circuits and lesions of the cerebellum do not abolish the learned behavior completely. Furthermore, experiments in mice are performed using freely moving systems, which lack the stability necessary for mapping out the essential neural circuitry with electrophysiological approaches. We have developed a novel apparatus for eyeblink conditioning in head-fixed mice. Here, we show that the performance of mice in our apparatus is excellent and that the learned behavior displays two hallmark features of cerebellardependent eyeblink conditioning in rabbits: (1) gradual acquisition; and (2) adaptive timing of conditioned movements. Furthermore, we use a combination of pharmacological inactivation, electrical stimulation, single-unit recordings, and targeted microlesions to demonstrate that the learned behavior is completely dependent on the cerebellum and to pinpoint the exact location in the deep cerebellar nuclei that is necessary. Our results pave the way for using eyeblink conditioning in head-fixed mice as a platform for applying next-generation genetic tools to address molecular and circuit-level questions about cerebellar function in health and disease.

Key words: cerebellum; classical conditioning; interpositus; mouse; neurophysiology; timing

\section{Introduction}

Pavlovian eyeblink conditioning is a simple associative task that has proven particularly useful for investigating the neural mechanisms underlying motor learning (Medina et al., 2000). In the simplest version, animals learn to blink in response to an initially neutral conditioned stimulus (CS; e.g., a tone), if it is repeatedly paired with an eyeblink-eliciting unconditioned stimulus (US; e.g., a periocular air puff). The learned blink, which is known as the eyelid conditioned response (CR), displays two hallmark features of motor learning tasks. First, CRs are acquired slowly over the course of many CS-US pairings (Hilgard and Marquis, 1935, 1936; Hilgard and Campbell, 1936; Schneiderman et al., 1962; Skelton, 1988; Ivarsson and Svensson, 2000). Second, CRs are precisely timed such that the time of maximum eyelid closure matches the interval separating the CS and the US during training (Boneau, 1958; Mauk and Ruiz, 1992; Domingo et al., 1997; Freeman et al., 2003; Koekkoek et al., 2003). The success of eyeblink conditioning as a model to study the neural basis of motor learning can be traced back to a series of groundbreaking experiments

Received July 10, 2014; revised Sept. 4, 2014; accepted Sept. 23, 2014.

Author contributions: S.A.H., M.P.W., S.N.C., L.I.R., and J.F.M. designed research; S.A.H., M.P.W., and S.N.C. performed research; S.A.H., M.P.W., and S.N.C. analyzed data; S.A.H. and J.F.M. wrote the paper.

This work was supported by the Searle Scholars Program and National Institutes of Health Grant R01 MH093727 (J.F.M.). We thank K. Ohmae and D. Subramanian for assistance with behavioral data collection and histology. S. Wang, I. Ozden, A. Giovannucci, and F. Najafi helped develop the original "floating ball" apparatus for eyeblink conditioning on which our "rotating treadmill" is based. S. Koekkoek, H-J. Boele, and C. DeZeeuw provided technical advice and helped with early versions of the eyeblink conditioning set up.

The authors declare no competing financial interests.

Correspondence should be addressed to Javier Medina, Department of Psychology, University of Pennsylvania, 3720 Walnut Street, Philadelphia, PA 19104. E-mail: jmed@psych.upenn.edu.

DOI:10.1523/JNEUROSCI.2820-14.2014

Copyright $\odot 2014$ the authors $\quad 0270-6474 / 14 / 3414845-09 \$ 15.00 / 0$ in rabbits (McCormick et al., 1982; McCormick and Thompson, 1984a; Krupa et al., 1993). This work identified the cerebellum as the key component of the neural circuitry necessary for the initial learning and the subsequent expression of CRs in these animals (Christian and Thompson, 2003).

In mice, the role of the cerebellum has been more difficult to ascertain. First, mice do not tolerate restraint as well as rabbits, so mouse eyeblink conditioning experiments are typically done using freely moving systems (De Zeeuw et al., 2004), which present unique challenges for using neurophysiological approaches that could help identify the relevant circuitry. Second, the properties of eyelid CRs differ significantly between mice and rabbits, calling into question whether the same neural systems are involved. For example, mice can learn very quickly in just a few conditioning trials (Vogel et al., 2002; Woodruff-Pak, 2006; Boele et al., 2010), and their CRs usually start with a fixed short-latency eyelid movement that is not properly timed (Aiba et al., 1994; Kishimoto et al., 2001, 2002; Koekkoek et al., 2003; Wada et al., 2007). These behavioral properties do not match what would be expected for a motor learning task, hinting instead at a possible contribution from fear conditioning circuits (Lennartz and Weinberger, 1992; Vogel et al., 2002; Boele et al., 2010). Indeed, recent studies indicate that mouse CRs are not always entirely driven by the cerebellum (Koekkoek et al., 2003, 2005; Sakamoto and Endo, 2008, 2010) and may include an amygdala-dependent component (Boele et al., 2010; Sakamoto and Endo, 2010).

We have developed a new apparatus for eyeblink conditioning in head-fixed mice, with the goal of isolating the motor learning component of the behavior and assessing whether it is cerebellar dependent. Our experiments were designed to evaluate, for the first time in individual mice, whether eyeblink conditioning dis- 
plays two hallmark features of motor learning tasks: (1) gradual acquisition and (2) adaptive timing. Because our mice were head fixed, we were able to perform functional mapping experiments in the cerebellum with unprecedented spatial resolution, taking advantage of neurophysiological tools to pinpoint the exact location in the deep cerebellar nuclei (DCN) that is critical for the expression of CRs.

\section{Materials and Methods}

Subjects. All experiments were performed in adult male C57BL/6 mice (The Jackson Laboratory). Mice were singly housed in a room with an inverted light/dark cycle (7:00 A.M. lights off, 7:00 P.M. lights on), and all experiments took place during the dark phase. Procedures were performed in accordance with protocols approved by the University of Pennsylvania Animal Care and Use Committee based on guidelines of the National Institutes of Health.

Surgical procedures. Before all experiments, stereotaxic surgery was performed to implant a "head plate." Mice were anesthetized with isoflurane $\left(1.5-2 \%\right.$ by volume in $\mathrm{O}_{2}$; SurgiVet) and kept on a heating pad to maintain body temperature. In addition, Meloxicam was given perioperatively to reduce swelling and provide postoperative analgesia. A midline incision was made to expose the skull, and the underlying fascia was cleared with cotton swabs. Two small screws were placed on either side of the midline near bregma. A thin stainless steel or aluminum head plate was then placed over bregma such that the screws fit into the central hole in the head plate (Fig. $1 B, C$ ) and secured to the screws and skull using Metabond cement (Parkell). A mark was placed in the cement to indicate the location of bregma so that stereotaxic measurements could be made during experiments.

In some mice $(n=12)$, a cannula (Plastics One) targeting the DCN was implanted by drilling a small hole in the skull overlying the cerebellum and stereotaxically guiding the bottom of the cannula into a position $1.8 \mathrm{~mm}$ above the target. The cannula was then permanently affixed with Metabond, and an internal "dummy" cannula that extended to the end of the guide cannula was inserted to prevent clogging while the mouse was in its home cage. In other mice $(n=4)$, a $3 \mathrm{~mm}$ craniotomy centered $\sim 6.5 \mathrm{~mm}$ posterior and $2.0 \mathrm{~mm}$ lateral from bregma was performed to allow access to the cerebellar cortex and deep nuclei for microstimulation and neural recording experiments. A plastic ring (inner diameter, 3.5 $\mathrm{mm}$ ) serving as a chamber was then implanted over the craniotomy and affixed to the skull with dental acrylic (Jet). A thin layer of antibiotic ointment was applied on top of the dura, and the chamber was filled with a fast-curing silicone elastomer (Kwik Sil; WPI), which could be removed before each daily experiment to give access to the brain. A stainless steel screw was implanted in the bone above the contralateral cerebellum to serve as a reference for microstimulation and neural recording.

Apparatus. The basic components of the head-fixed eyeblink conditioning system are shown in Figure $1 A$. The apparatus consists of a foam cylinder mounted to an axle via low-friction bearings, posts, and clamps to hold the cylinder in the air and a breadboard for mounting the various components (full parts list in Table 1). During experiments, the mouse's head plate (see above, Surgical procedures) was attached to a pair of machined rods via 2-56 machine screws (Fig. $1 B-D)$, and the mouse was free to walk on top of the cylinder at will. A high-speed camera and infrared illumination directed at the side of the mouse's face were mounted on a separate post via knuckle joints. Additional posts and clamps (not shown) were used to hold a plastic tube connected to a 23 gauge needle for the air-puff US and either an LED for a light CS or a plastic tube for a vibrissal CS, as described below.
For neurophysiology experiments, a microdrive was mounted on another post such that electrodes could be driven in and out of the brain on a daily basis through a craniotomy (see above, Surgical procedures). To facilitate stereotaxic placement of the electrode a microscopic camera (DynaLite) was placed above the craniotomy to allow live visualization of the electrode as it was lowered into place. To provide additional recording stability, the entire rig was mounted on a breadboard sitting atop a vibration isolation table (Newport) instead of the breadboard listed in Table 1.

Eyeblink conditioning. Mice were habituated to head restraint for $2 \mathrm{~d}$ before beginning the conditioning sessions by placing them on top of the foam cylinder with their heads fixed for $1 \mathrm{~h}$. No stimuli were delivered during this time. We then began several daily sessions (typically a single session comprising 100 trials each day) of CS-US pairing with interstimulus intervals (ISIs) ranging from 100 to $400 \mathrm{~ms}$. In some experiments, there were occasional test trials in which the CS was presented without the US. The intertrial interval (ITI) was set to a minimum of $10 \mathrm{~s}$, but the actual ITI varied slightly because trials were only initiated if the eyelids were open $>70-80 \%$ and were stable for at least $200 \mathrm{~ms}$ (median ITI, $11.0 \mathrm{~s} ; 85 \%$ of ITIs fell within $5 \mathrm{~s}$ of the minimum for all mice). These criteria were occasionally relaxed during periods of squinting, which was rare.

CSs were either an LED pulse of blue light or a weak puff of air (2-3 psi) directed at the vibrissal pad contralateral to the conditioned eye (Carrel et al., 2012). The pressure of the vibrissal air puff was set so that it did not produce any reflexive eyelid movements. The US was a puff of air $(20-30$ psi) of 20-30 ms duration directed at the cornea via a 23 gauge needle placed $3 \mathrm{~mm}$ from the mouse's eye. The pressure and duration of the periocular air puff were set for each mouse to produce a full reflexive blink (UR) when delivered alone. The CS and US coterminated or, for timing experiments, the CS remained on for $500 \mathrm{~ms}$ regardless of ISI.

High-speed videography. Eyelid movements were monitored under infrared illumination using a high-speed (200 or 350 frames/s) monochrome camera (Allied Vision) interfaced with MATLAB using customwritten software and the Video Acquisition Toolbox.

We developed two different algorithms for measuring eyelid movements from the high-speed videos (Fig. 2), both of which were fast enough to be used in real time during the experiment. The first used an area measurement to calculate the fraction of eyelid closure (FEC) frame by frame (Fig. 2, top). A region of interest (ROI) was selected, corresponding to the pupil, iris, and immediately surrounding fur when the eye was fully open. For each frame, the grayscale values of the pixels in the ROI were converted to binary by setting a threshold such that the pupil 
Table 1. Parts list for head-fixed eyeblink conditioning apparatus

\begin{tabular}{|c|c|c|c|c|}
\hline Label in Figure 1 & Item & Quantity & Supplier & Part number \\
\hline \multicolumn{5}{|l|}{ Treadmill system } \\
\hline 1 & Breadboard for mounting all hardware & 1 & Thorlabs & MB12 \\
\hline 2 & 1-inch-diameter post ( 3 or 6 inch length) & 2 & Thorlabs & RS3/RS6 \\
\hline 3 & Clamps for $1 / 4$ inch rod & 2 & Custom-made & \\
\hline 4 & $1 / 2$-inch-diameter post ( 6 inch length) & 2 & Thorlabs & TR6 \\
\hline 5 & Right-angle mounts for $1 / 2$-inch-diameter posts & 2 & Thorlabs & RA90 \\
\hline \multirow[t]{4}{*}{6} & $1 / 2$ inch brass or steel rods & 2 & Custom-made & \\
\hline & Head plate $(1 \times 5 / 16 \times 1 / 32$ inches $)$ & $1 /$ mouse & Custom-made & \\
\hline & Screws for fixing head plate to skull & $2-3$ & Amazon (Antrin) & AMS120/1F \\
\hline & Screws for attaching head plate to brass rods & 2 & McMaster-Carr & $91735 A 003$ \\
\hline 10 & Foam cylinder & 1 & Amazon (Exervo) & TERANOVA \\
\hline 11 & $1 / 4$-inch-diameter aluminum rod & 1 & McMaster-Carr & $9061 K 33$ \\
\hline 12 & Ball bearings for cylinder & 2 & McMaster-Carr & $3759 T 37$ \\
\hline \multicolumn{5}{|l|}{ Camera } \\
\hline & Ethernet card for camera communications & 1 & Intel & PWLA8391GT PR0/1000 GT PCI \\
\hline \multirow[t]{3}{*}{7} & High-speed camera & 1 & Allied Vision Technologies & GE680 \\
\hline & Lens for camera & 1 & Tamron & TAM-23FM25-L \\
\hline & Extension tubes for lens & 1 & 1stVision & LE-EX-10 \\
\hline \multirow[t]{3}{*}{8} & Infrared light source & 1 & Bosch & EX12LED \\
\hline & 1-inch-diameter post ( 3 or 6 inch length) & 1 & Thorlabs & $\mathrm{RS} 3 / \mathrm{RS} 6$ \\
\hline & $1 / 2$-inch-diameter post ( 6 inch length) & 2 & Thorlabs & TR6 \\
\hline \multirow[t]{3}{*}{9} & Knuckle joint & 2 & Panavise & $851-00$ \\
\hline & 1/2-inch-diameter post ( 2 or 3 inch length) & 2 & Thorlabs & TR2/TR3 \\
\hline & Right-angle mounts for $1 / 2$-inch-diameter posts & 2 & Thorlabs & RA90 \\
\hline \multicolumn{5}{|l|}{ Eyeblink specific } \\
\hline & Sound attenuating behavior box & 1 & Med Associates & ENV-022S \\
\hline & Needle for puff delivery & 1 & $B-D$ & 305143 \\
\hline & Tubing for air-puff delivery & & Clippard & URH1-0402-CLT \\
\hline & Pressure injector for air puffs & 1 & Applied Scientific Instrumentation & MPPI-3 \\
\hline & LED, tone generator, or additional pressure injector for CS & 1 & Various & Various \\
\hline
\end{tabular}

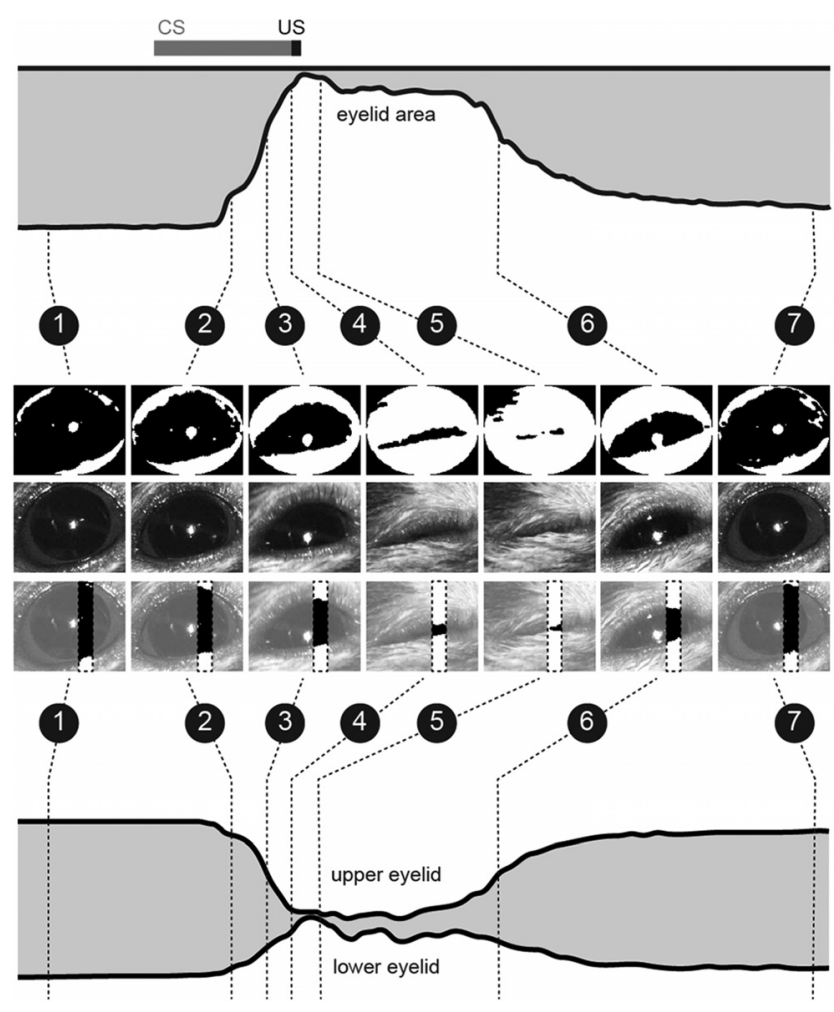

Figure 2. Eyelid movement detection algorithms. Illustration of algorithms used to measure eyelid closure using FEC (top panels) and eyelid edge position (bottom panels). Key time points during a paired CS-US trial are indicated by numbered lines connecting video frames to the corresponding points in the eyelid traces. and iris had a value of 0 and the fur a value of 1 . To eliminate "salt and pepper" noise in the binary image, a $5 \times 5$ pixel median filter was applied to the grayscale image before converting it to binary. Then, the values of all the pixels in the ROI were summed to calculate the area consisting of fur in each frame. These raw pixel counts were normalized into units of FEC, which ranges from 0 (fully open) to 1 (fully closed). Because the ROI has an elliptical shape, the FEC is proportional to the distance between the two eyelids (i.e., minor axis of the ellipse).

The second method gives a direct readout of the upper and lower eyelid positions (Fig. 2, bottom). A narrow rectangular window $\sim 25 \times$ 150 pixels was selected such that its long axis extended from the fur of the upper eyelid, through the center of the pupil, to the fur of the lower eyelid. If the reflection of the infrared light fell on the center of the pupil, the window was moved slightly off center. For each frame in the movie, the median pixel intensity was taken along the short axis to give an $\sim 1 \times$ 150 pixel vector of grayscale values. This grayscale vector was then converted to a binary image as in the FEC calculation. Going from top to bottom in the resulting binary vector, the transitions from white (1) to black (0) and black to white give, respectively, the position of the upper and lower eyelids in pixel units.

The two methods gave consistent results for all properties assessed in this study, but we have exclusively used the "area" method for all analyses and figures.

Pharmacological inactivation. Reversible inactivation of DCN was accomplished with muscimol (1 mM) or lidocaine (4\%) infusions through an implanted cannula (see above, Surgical procedures). In some sessions, fluorescent muscimol ( $1 \mathrm{~mm}$; BODIPY TMR-X muscimol conjugate; Invitrogen) was used instead. Before an infusion, an internal cannula connected to a $1 \mu$ l Hamilton syringe was inserted into the implanted cannula such that the tip protruded $1.8 \mathrm{~mm}$ from the bottom. The mouse was then given at least 30 baseline trials and the session was stopped to infuse the drug $(0.1-0.15 \mu \mathrm{l})$ over the course of $1 \mathrm{~min}$. Conditioning trials began again within 3 min of the infusion. At the end of the session, the internal cannula was carefully removed and replaced with the 
dummy cannula. Once outside the brain, the internal cannula was tested for clogging by depressing the syringe an additional $0.1 \mu \mathrm{l}$, and the session was excluded from analysis if this did not produce a visible drop at the tip ( $<10 \%$ of all sessions).

Microstimulation. Functional mapping of DCN was performed using 80 - $\mu \mathrm{m}$-diameter platinum iridium monopolar electrodes $(100 \mathrm{~K} \Omega$; Alpha Omega). Electrodes were positioned using stereotaxic coordinates relative to a mark on the cement (see above, Surgical procedures). Mapping was mostly confined to the anterior interpositus (AIP), dorsolateral hump (DLH), and lateral nucleus (LN). Electrodes were advanced in steps of $100 \mu \mathrm{m}$, and currents in the range of $1-15 \mu \mathrm{A}$ (200 ms pulse trains; $250 \mu$ s biphasic pulses; $500 \mathrm{~Hz}$ ) were systematically tested to identify the threshold for evoking movement.

Neural recording. Single-unit recordings were performed using 80$\mu \mathrm{m}$-diameter 2-5 $\mathrm{M} \Omega$ tungsten microelectrodes (FHC), which were reinforced by gluing them inside hypodermic tubing, attached to a micromanipulator (David Kopf Instruments). Spikes were sorted using principal component analysis after the extracellular signals had been digitized at $25 \mathrm{kHz}$ and bandpass filtered between 0.1 and $8 \mathrm{kHz}$ (System 3; Tucker Davis Technologies). Because of the stability of the head-fixed apparatus, single-unit recordings were remarkably stable during trials, and most neurons remained well isolated while the mice intermittently walked on the treadmill and groomed between trials (see Fig. $6 D$; SNR, $2.9 \pm 0.5$, mean $\pm \mathrm{SD} ; n=16$ ). The duration of recordings was generally limited more by the number of trials that the mice could perform than by the ability to maintain single-unit isolation, because $56 \%$ of neurons remained isolated for $>45 \mathrm{~min}$.

Lesions. In mice used for pharmacological experiments (see above, Pharmacological inactivation), electrolytic lesions were performed as terminal experiments to mark the location targeted by the implanted cannulae. A $10 \mathrm{~s}$ pulse of $100 \mu \mathrm{A}$ cathodal current was delivered through the cut end of an insulated stainless steel wire placed at the same depth as the internal cannula tip. In some of the mice used for neurophysiology experiments (see above, Neural recording), an electrolytic microlesion was made for mapping regions of the AIP nucleus necessary for CR expression. Pulses of cathodal current (10 s) were delivered through the tip of a 2-5 M $\Omega$ recording electrode. The intensity of the current was gradually increased in steps of $10 \mu \mathrm{A}$ until CRs were completely abolished, with the minimum required being $10 \mu \mathrm{A}$ and the maximum being $50 \mu \mathrm{A}$.

Histology and imaging. Mice were deeply anesthetized with isoflurane and transcardially perfused with $0.1 \mathrm{M}$ PBS, followed by $4 \%$ paraformaldehyde in $0.1 \mathrm{M}$ PBS. Brains were postfixed overnight and cryoprotected in $30 \%$ sucrose until they equilibrated (1-2 d). Coronal sections were cut at $50 \mu \mathrm{m}$ thickness on a cryostat (Leica) and immediately mounted on a glass slide. For mice with lesions (see Lesions), mounted sections were stained with cresyl violet using standard histological procedures, dehydrated, defatted, and coverslipped. For mice injected with fluorescent muscimol (see above, Pharmacological inactivation), mounted sections were stained with NeuroTrace Green Fluorescent Nissl (Invitrogen) using the vendor-recommended protocol with a 100-fold dilution of the stain and coverslipped with Prolong Gold (Invitrogen). Sections were imaged on a wide-field microscope (Zeiss Axioplan 2 or Olympus BX50) under bright-field (cresyl violet) or epifluorescent illumination.

Data analysis. Data were analyzed in MATLAB using custom-written software. Eyelid traces for each trial were extracted from the video frames using the area (FEC) algorithm, as described above (see High-speed videography). CR amplitudes on paired trials were calculated by subtracting the mean FEC in a $20 \mathrm{~ms}$ window preceding the US from the mean FEC in the first $20 \mathrm{~ms}$ after the CS. Trials were considered to contain a CR if this amplitude was $>10 \%$ of full closure. The time of maximum eyelid closure (i.e., the peak time) was calculated for every CS-alone trial with a $\mathrm{CR}$, by taking the time of maximum FEC during the entire duration of the CS. Mean and SDs of peak times for individual mice were estimated from the parameters of Gaussian fits to their peak time distributions.

\section{Results}

We have developed a new apparatus for performing eyeblink conditioning in head-fixed mice. The experiments described be-
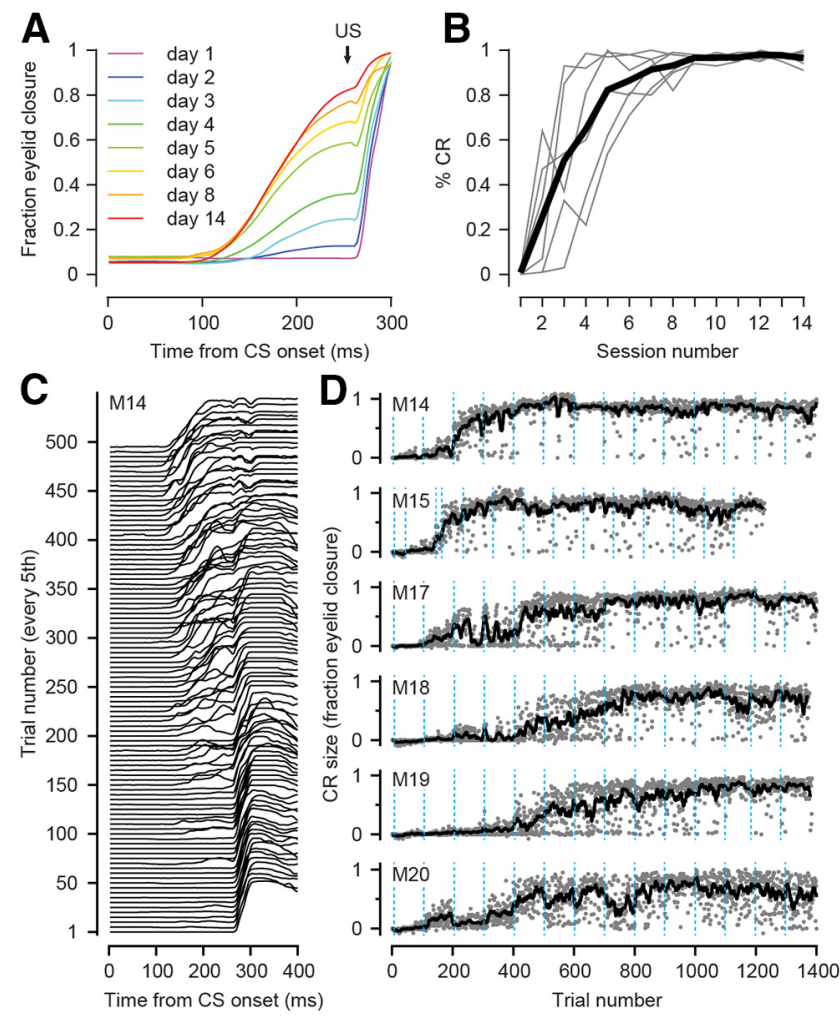

Figure 3. Learning curves for eyelid CRs. A, Average eyelid position traces during the ISI period (250 ms) for six mice throughout $14 \mathrm{~d}$ of conditioning to a light CS. Each trace is an average of the session-averaged traces of all six mice for the given session number. $B, \% C R$ during each session for the same six mice as in $\boldsymbol{A}$. Gray traces are individual mice, and black trace is the average of all mice. $C$, Example eyelid traces in individual trials for one mouse during the first five sessions. Only the trace for every fifth trial is plotted for clarity. D, CR amplitudes of individual mice for every trial (gray dots). Black traces are moving averages of individual trials (11 trial window). Blue dotted lines indicate session boundaries. Mouse identification numbers are indicated in the top left of each panel.

low were designed with three goals in mind: (1) to assess whether the eyelid CRs of individual mice display two behavioral features that are hallmarks of cerebellar-dependent motor learning tasks; (2) to test the hypothesis that the CRs are entirely driven by cerebellar circuits; and (3) to identify which areas of the DCN are critical for CR expression.

\section{CRs are gradually learned}

Figure $3 A$ shows the average eyelid CR amplitude of six mice trained for 14 consecutive sessions with a $250 \mathrm{~ms}$ CS-US interval $(\sim 100$ trials per session; US onset indicated by arrow). As is evident in these traces, the average CR amplitude gradually built up session after session. Over the same training period, the mice gradually increased the percentage of trials in which they generated a CR (\%CR; based on a threshold criterion of $10 \%$ eyelid closure), eventually producing CRs in $>90 \%$ of trials (Fig. $3 B$ ). The gradual increases in CR amplitude and \%CR were apparent in the trial-by-trial data of individual mice as well (Fig. $3 C, D$; median number of trials to go from $20 \%$ to $80 \%$ full eyelid closure, 244; range, 60-414), which indicates that these gradual effects are not simply attributable to averaging (Gallistel et al., 2004). Mice showed a range of learning rates but all reached asymptotic performance by trial 900 (beginning of session 9), reliably closing their eyelids almost all the way (75-80\% closure) just before the delivery of the puff US. Importantly, none of the mice showed any evidence of having learned the CR in the first 

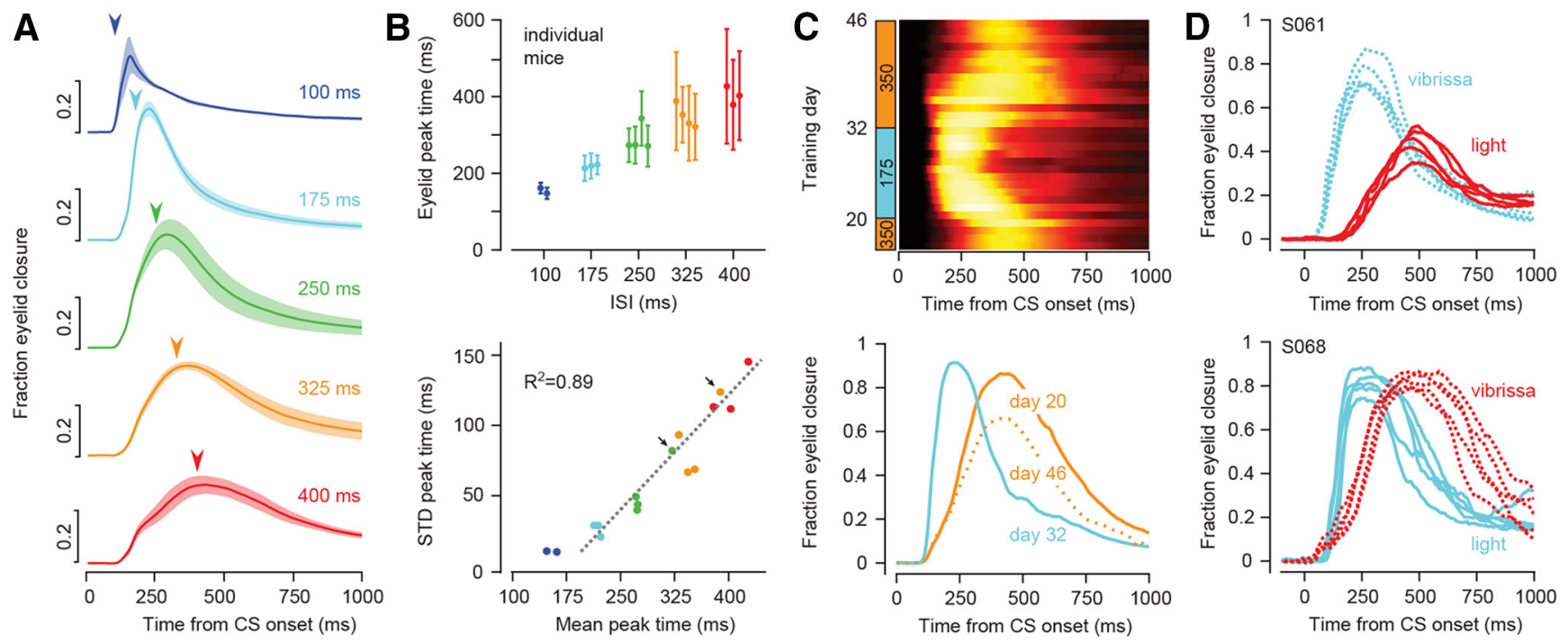

Figure 4. Timing of eyelid CRs. A, Average eyelid position traces on CS-only trials for each ISI group. Trained ISI is indicated above each trace. Error clouds are SEM based on per mouse averages. Arrowheads indicate expected time of the puff. $\boldsymbol{B}$, Scalar property of CR timing. Top, Average time of peak CR for individual mice from $\boldsymbol{A}$ (groups indicated by color). Error bars indicate SD. Bottom, SDs plotted against mean peak times for the same mice using the same color code. For an explanation of the arrows, see Results. The dotted line is a linear fit, with the corresponding $R^{2}$ value, for data from all ISls except $100 \mathrm{~ms}$, which produced small and poorly timed CRs. C, Learned shifts of CR times. Top, Heat map of the average CR traces for CS-alone trials of each session during shifts from long to short and then short to long ISIs in a single mouse. Color indicates average CR amplitude at each time point (black $<$ red $<$ white). Each row is a different session, and the ISI for that session is indicated along the $y$-axis. Bottom, Average eyelid traces for the indicated sessions, which correspond to the last session before a switch $(20,32)$ or the final session (46). $\boldsymbol{D}$, Average CR traces on CS-alone trials for five sessions from single mice trained with two different CS modalities that had different corresponding ISls. Top, $200 \mathrm{~ms}$ vibrissa, $400 \mathrm{~ms}$ light. Bottom, $200 \mathrm{~ms}$ light, $400 \mathrm{~ms}$ vibrissa. All panels use similar color scheme to indicate ISIs as in $\boldsymbol{A}$. Mouse identification numbers are indicated in the top left of each panel.

session (Fig. 3D), which is consistent with the slow acquisition rates reported in many motor learning tasks (Schmidt and Lee, 2013) and with previous studies of eyeblink conditioning in other animal species, including rabbits (Schneiderman et al., 1962).

\section{CRs are adaptively timed}

To examine the timing of CRs, we started by analyzing conditioned eyelid movements in one of our previous datasets (Chettih et al., 2011). In this experiment, we first trained mice with one of five different CS-US intervals (ISI) and subsequently measured eyelid movements in sessions that had a small number of randomly interleaved CS-alone trials in which we omitted the US (Fig. 4A). For mice trained with the $100 \mathrm{~ms}$ ISI, which is close to the minimum eyelid movement latency for a visual CS, the eyelids failed to accelerate fast enough and were $<5 \%$ closed at the expected time of the US (Fig. $4 A$, blue arrow). Mice trained with longer ISIs performed better, reaching peak eyelid closure around the expected time of the US (Fig. 4A). Although the CRs were well timed on average, the exact time of peak closure became increasingly variable at longer ISIs (Fig. 4B). This resulted in a linear relationship between the mean and the SD of peak times over a wide range of ISIs (Fig. $4 B$, bottom), which is a characteristic feature of CRs that is seen in other species as well (Gallistel and Gibbon, 2000; White et al., 2000; Vogel et al., 2003). Interestingly, the amount of variability in the timing of the CR was more strongly correlated with the mean time of maximum eyelid closure than the particular ISI used for training (Fig. $4 B$, bottom, arrows). However, in contrast to rabbits (Mauk and Ruiz, 1992), the mice did not appear to regulate CR timing by changing the latency of the response (see analysis within Chettih et al., 2011).

The data in Figure 4, $A$ and $B$, provide a between-animal comparison but do not answer whether individual mice can adjust the timing of CRs adaptively. To assess this possibility, we designed two additional experiments. First, we trained mice with one ISI for many consecutive sessions and then switched the ISI to a different value. We found that the timing of CRs shifted gradually over the course of several sessions and eventually reached an asymptote that was appropriate for the new ISI, when the ISI was shifted both from longer to shorter or shorter to longer values (Fig. 4C). Second, we trained individual mice on a differential conditioning task in which one CS (light) was paired with the US at one interval in $50 \%$ of the trials in a session, and a different CS (vibrissa) was paired with the US at a second interval in the remaining $50 \%$ of the trials. As shown in the average eyelid position traces of CS-alone trials, for each of the last five sessions of conditioning (Fig. 4D), mice learned to generate CRs that were appropriately timed for the particular CS presented on any given trial. Overall, our results clearly demonstrate that, as is the case in other species (Kehoe and Napier, 1991; Mauk and Ruiz, 1992), head-fixed mice in our apparatus learn to adaptively regulate the timing of the CR and achieve maximum eyelid closure at the time of the US under a wide range of stimulus contingencies. Importantly, we did not observe the fixed short-latency eyelid movements that have been reported in freely moving mice trained with an auditory CS (Vogel et al., 2002; Boele et al., 2010).

\section{CRs are cerebellar dependent}

In 12 mice, we used pharmacological inactivation to assess the contribution of the cerebellum to CR expression. This pharmacological approach has been used to demonstrate that CRs are entirely driven by cerebellar circuits in rabbits (Clark et al., 1992; Krupa et al., 1993; Christian and Thompson, 2003) and rats (Freeman et al., 2005). After training the mice for several sessions (light CS; $250 \mathrm{~ms}$ ISI), we infused the GABA agonist muscimol (1 $\mathrm{mM}, 0.10-0.15 \mu \mathrm{l})$ through an implanted cannula targeting anterior regions of the DCN. Before the infusion, the mice performed at least 30 trials to help establish a baseline performance (Fig. 5A, D; blue). For mice with cannulae implanted 5.8-6.0 $\mathrm{mm}$ posterior to bregma (Fig. $5 C$, circles; $n=7$ ), infusion in the vicinity of AIP, LN, or DLH caused a complete wipeout of the CR 
beginning on the first or second trial after the infusion and lasting for the remainder of the session (Fig. $5 A, D$; red arrow in $A$ indicates time of infusion). This effect was not simply attributable to a nonspecific response to the infusion procedure because vehicle infusions had no effect (Fig. $5 D$ ), and infusion of the short-lasting sodium channel blocker lidocaine through the same cannula $(4 \%, 0.10-0.15 \mu \mathrm{l}) \mathrm{re}$ sulted in similar immediate effects on CR amplitude (Fig. $5 B, D$, red), but the CRs recovered within $15-20 \mathrm{~min}$ (Fig. $5 B, D$, green). In addition, the mice continued to blink normally in response to the periocular air-puff stimulus during all our infusions (Fig. 5A,B), which excludes the possibility that the wipeout of the CR was caused by a generalized impairment in motor performance.

Two additional observations provide some hints about the regions of $\mathrm{DCN}$ that are critical for CR expression. First, infusion of fluorescent muscimol (1 $\mathrm{mM}, 0.15 \mu \mathrm{l})$ in three of the mice revealed that the drug diffused only a few hundred micrometers from the infusion site in the AIP (diameter of spread, 416, 384 , and $210 \mu \mathrm{m}$, measured as 2 SDs along the dimension of maximum spread), as shown for one of these mice in Figure $5 E$. Second, infusions of muscimol near the middle cerebellar peduncle 5.5-5.7 mm from bregma or near the posterior interpositus $6.4-6.7 \mathrm{~mm}$ from bregma (Fig. $5 C, \times$ symbols; $n=5$ ) partially suppressed but did not wipe out the CR immediately or completely. These results suggest that, in our experiments, the areas of DCN necessary for generating CRs are located toward the most anterior regions of the AIP, similar to what has been observed in rabbits (Lavond et al., 1984b; Yeo et al., 1985).

\section{The anterolateral AIP is critical for CR expression}

To pinpoint the precise area of DCN responsible for the expression of CRs, we performed a series of electrophysiological mapping experiments. The strategy we used highlights the advantages of our head-fixed system for combining behavioral measurements with a variety of acute electrophysiological techniques. First, we made multiple stereotaxically guided electrode penetrations to map a small region of the AIP from which discrete, graded eyelid closure could be reliably evoked using electrical microstimulation with very low currents (see Materials and Methods). As shown in the eyelid traces and heat maps for two representative mice (Fig. $6 A, B$ ), the hotspot for evoking blinks was centered $\sim 1.5-1.8 \mathrm{~mm}$ lateral of the midline and was limited to the most anterior portion of the DCN (note that the anterior limit of DCN is located $5.6 \mathrm{~mm}$ posterior from bregma; Fig. $5 C$ ). We then used a recording electrode to search for neurons in this area whose activity was strongly modulated during the generation of CRs.

Figure $6 C$ shows the response of an example neuron that was recorded in the hotspot during paired trials. This neuron produced a large excitatory response that preceded the CR, a pattern of modulation that has been observed for AIP neurons in rabbits (McCormick and Thompson, 1984b; Berthier and Moore, 1990)
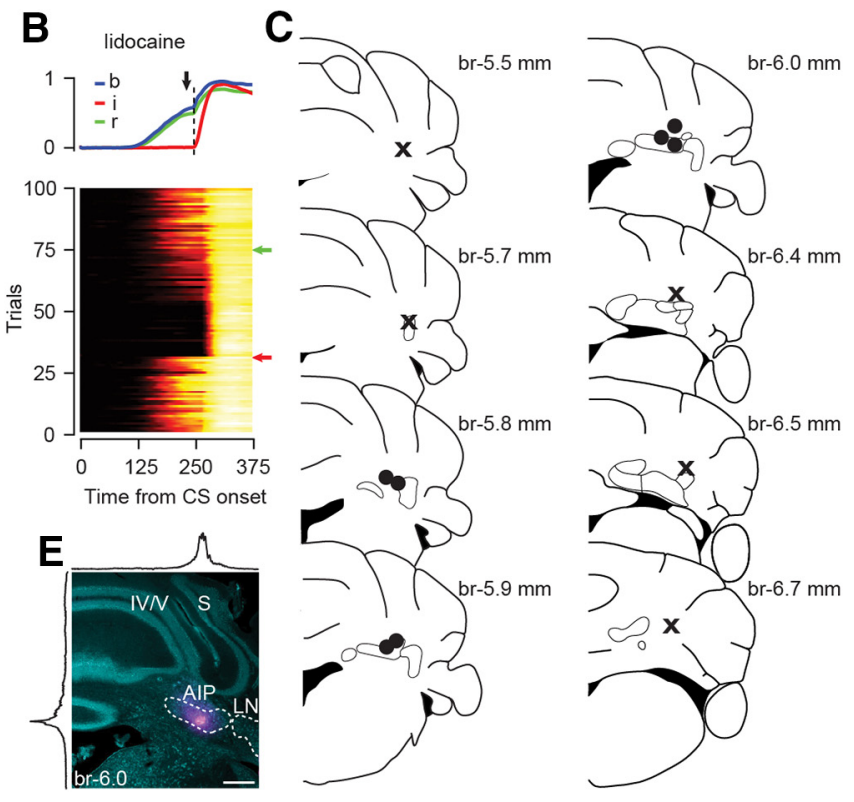

Figure 5. Pharmacological inactivation of DCN abolishes CRs. A, Bottom, Heat map showing average eyelid amplitude of seven mice during the ISI period $(250 \mathrm{~ms}$ ) on paired trials before and after muscimol infusion in the effective region (time of infusion show dorsoventral and mediolateral distribution of pixel intensities on the magenta (muscimol) channel for same section. The AIP, DLH, and LN outlined in white based on Nissl staining. Lobules IV/V and simplex (S) are labeled. Scale bar, $500 \mu \mathrm{m}$.

and rats (Freeman and Nicholson, 2000). We found a similar pattern across the population of neurons recorded near this location, as seen in the population average (Fig. $6 E$; mean $\pm \mathrm{SD}$ lead, $19.1 \pm 10.4 \mathrm{~ms} ; n=16)$. In three mice, we made a small electrolytic lesion (10-50 $\mu \mathrm{A}$ direct current, $10 \mathrm{~s}$ ) through the recording electrode immediately after finding a single unit with CR-related activation. In all cases, the lesions completely abolished CRs (Fig. 6F, right), and the CRs remained absent the following day. Histological examination revealed that these lesions were all confined to the same small region of the anterolateral AIP abutting the LN and DLH (Fig. 6F, left; maximum mediolateral extent of lesions, $207,294$, and $301 \mu \mathrm{m})$. This is the same small area of DCN that has been shown to be essential for the initial learning and subsequent expression of CRs in rabbits (Christian and Thompson, 2003).

\section{Discussion}

We have introduced a novel experimental apparatus to examine the behavioral properties of eyeblink conditioning in head-fixed mice and to identify which areas of the DCN are critical for CR expression. Our results demonstrate that the behavior of individual mice displays two hallmark features of motor learning tasks (Schmidt and Lee, 2013): (1) eyelid CRs were acquired slowly over the course of many training trials; and (2) their timing was adaptively controlled. Furthermore, we found a small region in the most anterior portion of the DCN that was necessary for generating eyelid CRs in well trained mice. Below, we discuss our findings in the context of the existing mouse and rabbit eyeblink literature and highlight some of the key advantages of our headfixed system for future experiments. 

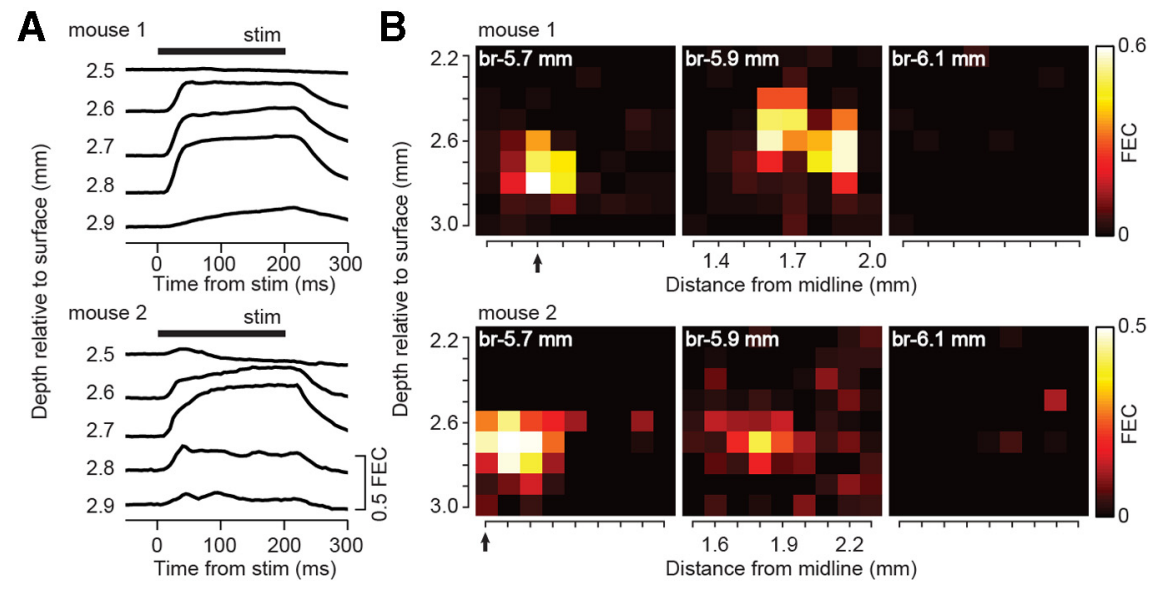

C
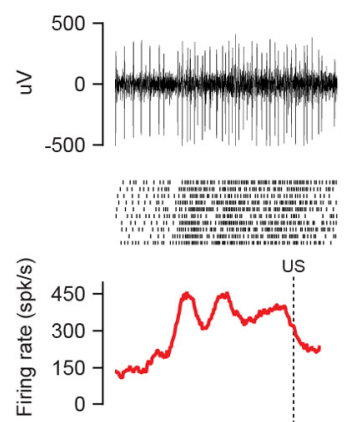

D

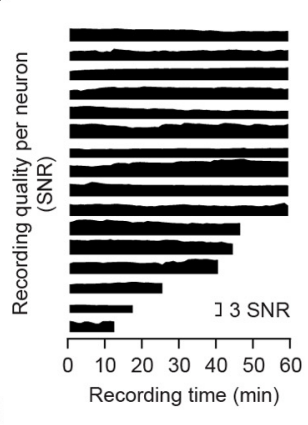

$F$

E
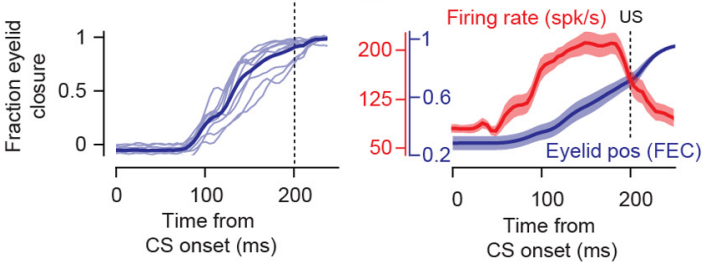

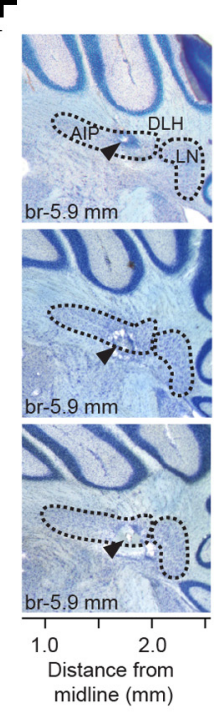

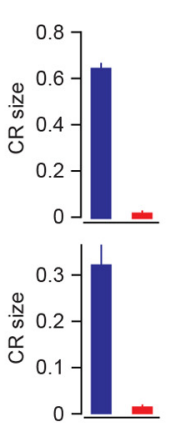

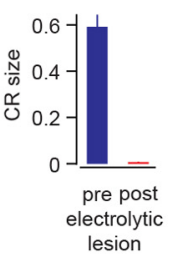

Figure 6. Electrophysiological localization of eyeblink hotspot. $A$, Individual traces of microstimulation-evoked eyelid movements at different depths near the hotspot for two different mice. Black bar indicates the duration of stimulation. $\boldsymbol{B}$, Heat maps showing microstimulation-evoked eyelid amplitude at different dorsoventral ( $y$-axis) and mediolateral ( $x$-axis) locations for three different anteroposterior sections in the same two mice (anteroposterior coordinate of each section is indicated relative to bregma; br). Each small square is the eyelid closure produced by $5 \mu \mathrm{A}$ (mouse 1) or $7 \mu \mathrm{A}$ (mouse 2) microstimulation at that precise location, measured as the mean eyelid position in the last $50 \mathrm{~ms}$ of stimulation, averaged across three trials. Heat maps are normalized by maximal movement size in each experiment (color bar indicates value corresponding to maximum). The order of locations visited in microstimulation tracks was counterbalanced in the two mice. Arrows below the $x$-axis indicate the track corresponding to the traces in $\boldsymbol{A}$. C, Example neuron recorded near the hotspot found using microstimulation as in $\boldsymbol{A}$ during paired trials in a mouse conditioned with a $200 \mathrm{~ms} I S \mathrm{I}$ and a light CS. From the top, Extracellular signal during a single trial, raster of spike times for 10 paired trials, peristimulus time histogram, and eyelid position trials for the same 10 trials (light thin traces). Average eyelid position trace indicated by dark thick trace. $\boldsymbol{D}$, Horizon plots showing the signal-to-noise ratio of recorded neurons over time ( $30 \mathrm{~s}$ moving average). Recordings were terminated after $1 \mathrm{~h}$ if the neuron was still isolated. $\boldsymbol{E}$, Average firing rate (red) and eyelid position (blue) on paired trials for 16 neurons recorded in hotspot. Error cloud indicates SEM. $\boldsymbol{F}$, Locations of lesions (triangles) in cresyl violet-stained coronal sections (left) and corresponding effect of lesion on CR amplitudes for three mice (right). Deep nuclei demarcated by dotted areas. Error bars indicate SEM.

\section{Similarities between mouse eyeblink conditioning and motor learning}

A hallmark of motor learning is that improvements in performance occur gradually and often require multiple training sessions (Squire, 1986; Schmidt and Lee, 2013). During eyeblink conditioning, for example, CRs are acquired slowly over the course of many conditioning trials in a variety of animal species, including humans (Hilgard and Campbell, 1936), monkeys (Hilgard and Marquis, 1936), dogs (Hilgard and Marquis, 1935), ferrets (Ivarsson and Svensson, 2000), rabbits (Schneiderman et al., 1962), and rats (Skelton, 1988). In contrast, previous studies

have reported that $\mathrm{CR}$ acquisition is much faster in mice and that performance can sometimes reach asymptote in the first session of conditioning (Vogel et al., 2002; Woodruff-Pak, 2006). It has been suggested that this rapid learning indicates the recruitment of additional neural circuits involved in fear conditioning (Boele et al., 2010). Such recruitment would open up an interesting avenue of research for looking at interactions between multiple systems (Lavond et al., 1984a; Neufeld and Mintz, 2001; Lee and Kim, 2004), but it would also diminish the utility of eyeblink conditioning as a behavioral model for studying neural mechanisms of motor learning in isolation. In our head-fixed apparatus, mice acquired the eyelid CR gradually over many trials and did not show any signs of learning in the first session of conditioning. The learning rate in our experiments was very similar to what has been reported in previous studies of eyeblink conditioning in rabbits (Schneiderman et al., 1962; Medina et al., 2001), which suggests that we were able to isolate the motor learning component of the task.

Mice trained in our head-fixed apparatus also displayed an additional behavioral signature of many motor learning tasks: adaptive timing (Schmidt and Lee, 2013). We found that individual mice learned to adjust the kinematic properties of the $\mathrm{CR}$ with millisecond precision, achieving maximum eyelid closure at the expected time of the US across a wide range of CS-US intervals and stimulus contingencies. To control CR timing, mice regulated the speed of the eyelid movement but not the latency to onset (Chettih et al., 2011), which differs from what is normally seen in other species, such as rabbits (Mauk and Ruiz, 1992), and may indicate distinct underlying mechanisms. Importantly, we did not observe the short-latency eyelid movements often reported in previous studies of eyeblink conditioning with freely moving mice (Aiba et al., 1994; Kishimoto et al., 2001, 2002; Koekkoek et al., 2003; Wada et al., 2007; Sakamoto and Endo, 2010). These short-latency responses (SLRs) are thought to originate in the amygdala (Boele et al., 2010; Sakamoto and Endo, 2010) and have a fixed onset regardless of CS-US interval that can complicate attempts to analyze CR timing with precision (Koekkoek et al., 2003; Boele et al., 2010). The lack of SLRs in our head-fixed apparatus provides an opportunity to follow up on groundbreaking studies about the molecular basis of motor timing in mice (Koekkoek et al., 2003), without interference from fear-related processes.

\section{Eyelid CRs are entirely driven by the cerebellum}

Much of the success that eyeblink conditioning has enjoyed as a behavioral model for studying the neural mechanisms of motor 
learning can be traced back to pioneering work demonstrating that the cerebellum is necessary for CR expression in rabbits (McCormick et al., 1982; Lavond et al., 1984b; McCormick and Thompson, 1984a; Krupa et al., 1993). Whether the cerebellum is also necessary for CR expression in mice has been less clear. A number of studies have shown that lesions or pharmacological inactivation of the $\mathrm{DCN}$ in freely moving mice impair CRs but do not wipe them out completely (Koekkoek et al., 2003, 2005; Sakamoto and Endo, 2008, 2010), suggesting that other noncerebellar sites, including the amygdala, play a prominent role (Boele et al., 2010; Sakamoto and Endo, 2010). In contrast, we found that, for mice trained in our head-fixed apparatus, eyelid CRs were entirely driven by cells located in the most anterior part of lateral AIP. This location coincides with the areas of DCN that are necessary for CR expression in rabbits (McCormick and Thompson, 1984a; Yeo et al., 1985) and is also in close proximity to areas of DLH and AIP that undergo structural plasticity during eyeblink conditioning in freely moving mice (Boele et al., 2013). Furthermore, this same region of DCN receives input from Purkinje cells capable of driving eyeblinks (Heiney et al., 2014). Our results are the first to pinpoint a critical component of the neural circuitry mediating the expression of CRs in mice, thus providing a target for genetic manipulation in future experiments looking to dissect the contribution of cerebellar mechanisms to motor learning.

\section{Advantages of our head-fixed apparatus}

Head-fixed preparations provide unparalleled reliability for controlling stimulus delivery and for simultaneously monitoring behavioral and neural activity in awake animals (Schwarz et al., 2010), which is why they are commonly used for neurophysiological studies in species that tolerate restraint well (Evarts, 1968; McCormick and Thompson, 1984a; Populin and Yin, 1998). In contrast, systems for head fixation in awake mice have lagged behind and have only recently begun to surface (Guo et al., 2014), partly because immobilizing these animals is more difficult and can sometimes cause stress-related impairments in behavior (Paré and Glavin, 1986; Li et al., 2012). One of the objectives in our study was to establish a paradigm for training head-fixed mice in a classical eyeblink conditioning task and to showcase some of its advantages over current freely moving systems (De Zeeuw et al., 2004).

Because our head-fixed system is suitable for high-speed videography, we were able to monitor the eyelid movements of our mice with unprecedented spatial and temporal resolution. Unlike EMG methods in freely moving systems (Aiba et al., 1994; Chen et al., 1996; Kishimoto et al., 2001, 2002; Vogel et al., 2002; Woodruff-Pak, 2006; Wada et al., 2007; Sakamoto and Endo, 2008 , 2010), which do not measure movement directly and in small animals like mice can be contaminated by the contraction of nearby facial muscles (Koekkoek et al., 2002), high-speed video provides a veridical readout of actual eyelid position. This makes it possible, for instance, to quantify the kinematics of the movement and to correlate them with neural activity (Heiney et al., 2014). Other techniques, such as those that rely on gluing a small magnet on the eyelid (Koekkoek et al., 2002; Chettih et al., 2011), provide excellent temporal resolution as well, but they add inertia to the motor plant and suffer from nonlinearities that complicate measurements (Koekkoek et al., 2002; De Zeeuw et al., 2004). In addition, our video system is the only method that can be used to resolve the positions of the top and bottom eyelid separately, thus enabling future investigations about the neural control and coordination of agonist/antagonist muscles (Evinger, 1995; Delgado-García et al., 2003).
One of the key advantages of head fixation is that it affords the structural stability necessary for performing neurophysiological and imaging experiments that would be much more challenging in freely moving mice (Schwarz et al., 2010; Chen et al., 2013). In the current study, we used a combination of pharmacological inactivation, electrical microstimulation, and single-unit recordings to functionally map the location of eyeblink-related regions in the mouse DCN. Previously, we had shown that the same head-fixed apparatus is also suitable for other neurophysiological approaches during nonconditioning experiments in awake mice, including optogenetic manipulation of cell-specific neural populations (Heiney et al., 2014) and two-photon calcium imaging of Purkinje cells (Najafi et al., 2014). This versatility, combined with the elegant simplicity of eyeblink conditioning and the powerful genetic tools available for mice (Heintz, 2001; Huang and Zeng, 2013), makes our head-fixed system an ideal tool for dissecting the neural mechanisms underlying motor learning in the vertebrate brain.

\section{References}

Aiba A, Kano M, Chen C, Stanton ME, Fox GD, Herrup K, Zwingman TA, Tonegawa S (1994) Deficient cerebellar long-term depression and impaired motor learning in mGluR1 mutant mice. Cell 79:377-388. CrossRef Medline

Berthier NE, Moore JW (1990) Activity of deep cerebellar nuclear cells during classical conditioning of nictitating membrane extension in rabbits. Exp Brain Res 83:44-54. Medline

Boele HJ, Koekkoek SKE, De Zeeuw CI (2010) Cerebellar and extracerebellar involvement in mouse eyeblink conditioning: the ACDC model. Front Cell Neurosci 3:19. CrossRef Medline

Boele HJ, Koekkoek SKE, De Zeeuw CI, Ruigrok TJH (2013) Axonal sprouting and formation of terminals in the adult cerebellum during associative motor learning. J Neurosci 33:17897-17907. CrossRef Medline

Boneau CA (1958) The interstimulus interval and the latency of the conditioned eyelid response. J Exp Psychol 56:464-471. CrossRef Medline

Carrel AJ, Zbarska S, Zenitsky GD, Bracha V (2012) A trigeminal conditioned stimulus yields fast acquisition of cerebellum-dependent conditioned eyeblinks. Behav Brain Res 226:189-196. CrossRef Medline

Chen JL, Andermann ML, Keck T, Xu NL, Ziv Y (2013) Imaging neuronal populations in behaving rodents: paradigms for studying neural circuits underlying behavior in the mammalian cortex. J Neurosci 33:1763117640. CrossRef Medline

Chen L, Bao S, Lockard JM, Kim JK, Thompson RF (1996) Impaired classical eyeblink conditioning in cerebellar-lesioned and Purkinje cell degeneration (pcd) mutant mice. J Neurosci 16:2829-2838. Medline

Chettih SN, McDougle SD, Ruffolo LI, Medina JF (2011) Adaptive timing of motor output in the mouse: the role of movement oscillations in eyelid conditioning. Front Integr Neurosci 5:72. CrossRef Medline

Christian KM, Thompson RF (2003) Neural substrates of eyeblink conditioning: acquisition and retention. Learn Mem 10:427-455. CrossRef Medline

Clark RE, Zhang AA, Lavond DG (1992) Reversible lesions of the cerebellar interpositus nucleus during acquisition and retention of a classically conditioned behavior. Behav Neurosci 106:879-888. CrossRef Medline

Delgado-García JM, Gruart A, Trigo JA (2003) Physiology of the eyelid motor system. Ann N Y Acad Sci 1004:1-9. CrossRef Medline

De Zeeuw CI, Elgersma Y, Hulscher HC, Dortland BR, Hensbroek RA, Ruigrok TJH, Koekkoek SKE (2004) Response to comment on "Cerebellar LTD and learning-dependent timing of conditioned eyelid responses." Science 304:211c-211c. CrossRef

Domingo JA, Gruart A, Delgado-García JM (1997) Quantal organization of reflex and conditioned eyelid responses. J Neurophysiol 78:2518-2530. Medline

Evarts EV (1968) Relation of pyramidal tract activity to force exerted during voluntary movement. J Neurophysiol 31:14-27. Medline

Evinger C (1995) A brain stem reflex in the blink of an eye. Physiology 10:147-153

Freeman JH Jr, Nicholson DA (2000) Developmental changes in eye-blink conditioning and neuronal activity in the cerebellar interpositus nucleus. J Neurosci 20:813-819. Medline

Freeman JH Jr, Nicholson DA, Muckler AS, Rabinak CA, DiPietro NT (2003) Ontogeny of eyeblink conditioned response timing in rats. Behav Neurosci 117:283-291. CrossRef Medline

Freeman JH Jr, Halverson HE, Poremba A (2005) Differential effects of cer- 
ebellar inactivation on eyeblink conditioned excitation and inhibition. J Neurosci 25:889-895. CrossRef Medline

Gallistel CR, Gibbon J (2000) Time, rate, and conditioning. Psychol Rev 107:289-344. CrossRef Medline

Gallistel CR, Fairhurst S, Balsam P (2004) The learning curve: implications of a quantitative analysis. Proc Natl Acad Sci U S A 101:13124-13131. CrossRef Medline

Guo ZV, Hires SA, Li N, O'Connor DH, Komiyama T, Ophir E, Huber D, Bonardi C, Morandell K, Gutnisky D, Peron S, Xu NL, Cox J, Svoboda K (2014) Procedures for behavioral experiments in head-fixed mice. PLoS One 9:e88678. CrossRef Medline

Heiney SA, Kim J, Augustine GJ, Medina JF (2014) Precise control of movement kinematics by optogenetic inhibition of Purkinje cell activity. J Neurosci 34:2321-2330. CrossRef Medline

Heintz N (2001) BAC to the future: the use of BAC transgenic mice for neuroscience research. Nat Rev Neurosci 2:861-870. CrossRef Medline

Hilgard ER, Campbell AA (1936) The course of acquisition and retention of conditioned eyelid responses in man. J Exp Psychol 19:227-247. CrossRef

Hilgard ER, Marquis DG (1935) Acquisition, extinction, and retention of conditioned lid responses to light in dogs. J Comp Psychol 19:29-58. CrossRef

Hilgard ER, Marquis DG (1936) Conditioned eyelid responses in monkeys, with a comparison of dog, monkey, and man. Psychol Monogr 47:186-198. CrossRef

Huang ZJ, Zeng H (2013) Genetic approaches to neural circuits in the mouse. Annu Rev Neurosci 36:183-215. CrossRef Medline

Ivarsson M, Svensson P (2000) Conditioned eyeblink response consists of two distinct components. J Neurophysiol 83:796-807. Medline

Kehoe EJ, Napier RM (1991) Temporal specificity in cross-modal transfer of the rabbit nictitating membrane response. J Exp Psychol Anim Behav Process 17:26-35. CrossRef Medline

Kishimoto Y, Kawahara S, Fujimichi R, Mori H, Mishina M, Kirino Y (2001) Impairment of eyeblink conditioning in GluRdelta2-mutant mice depends on the temporal overlap between conditioned and unconditioned stimuli. Eur J Neurosci 14:1515-1521. CrossRef Medline

Kishimoto Y, Fujimichi R, Araishi K, Kawahara S, Kano M, Aiba A, Kirino Y (2002) mGluR1 in cerebellar Purkinje cells is required for normal association of temporally contiguous stimuli in classical conditioning. Eur J Neurosci 16:2416-2424. CrossRef Medline

Koekkoek SKE, Den Ouden WL, Perry G, Highstein SM, De Zeeuw CI (2002) Monitoring kinetic and frequency-domain properties of eyelid responses in mice with magnetic distance measurement technique. J Neurophysiol 88:2124-2133. Medline

Koekkoek SKE, Hulscher HC, Dortland BR, Hensbroek RA, Elgersma Y, Ruigrok TJH, De Zeeuw CI (2003) Cerebellar LTD and learningdependent timing of conditioned eyelid responses. Science 301:17361739. CrossRef Medline

Koekkoek SKE, Yamaguchi K, Milojkovic BA, Dortland BR, Ruigrok TJH, Maex R, De Graaf W, Smit AE, VanderWerf F, Bakker CE, Willemsen R, Ikeda T, Kakizawa S, Onodera K, Nelson DL, Mientjes E, Joosten M, De Schutter E, Oostra BA, Ito M, De Zeeuw CI (2005) Deletion of FMR1 in Purkinje cells enhances parallel fiber LTD, enlarges spines, and attenuates cerebellar eyelid conditioning in Fragile X syndrome. Neuron 47:339-352. CrossRef Medline

Krupa DJ, Thompson JK, Thompson RF (1993) Localization of a memory trace in the mammalian brain. Science 260:989-991. CrossRef Medline

Lavond DG, Lincoln JS, McCormick DA, Thompson RF (1984a) Effect of bilateral lesions of the dentate and interpositus cerebellar nuclei on conditioning of heart-rate and nictitating membrane/eyelid responses in the rabbit. Brain Res 305:323-330. CrossRef Medline

Lavond DG, McCormick DA, Thompson RF (1984b) A nonrecoverable learning deficit. Physiol Psychol 12:103-110. CrossRef

Lee T, Kim JJ (2004) Differential effects of cerebellar, amygdalar, and hippocampal lesions on classical eyeblink conditioning in rats. J Neurosci 24:3242-3250. CrossRef Medline

Lennartz R, Weinberger N (1992) Analysis of response systems in Pavlovian conditioning reveals rapidly versus slowly acquired conditioned responses: support for two factors, implications for behavior and neurobiology. Psychobiology 20:93-119.
Li S, Fan YX, Wang W, Tang YY (2012) Effects of acute restraint stress on different components of memory as assessed by object-recognition and object-location tasks in mice. Behav Brain Res 227:199-207. CrossRef Medline

Mauk MD, Ruiz BP (1992) Learning-dependent timing of Pavlovian eyelid responses: differential conditioning using multiple interstimulus intervals. Behav Neurosci 106:666-681. CrossRef Medline

McCormick DA, Thompson RF (1984a) Cerebellum: essential involvement in the classically conditioned eyelid response. Science 223:296-299. CrossRef Medline

McCormick DA, Thompson RF (1984b) Neuronal responses of the rabbit cerebellum during acquisition and performance of a classically conditioned nictitating membrane-eyelid response. J Neurosci 4:2811-2822. Medline

McCormick DA, Clark GA, Lavond DG, Thompson RF (1982) Initial localization of the memory trace for a basic form of learning. Proc Natl Acad Sci U S A 79:2731-2735. CrossRef Medline

Medina JF, Nores WL, Ohyama T, Mauk MD (2000) Mechanisms of cerebellar learning suggested by eyelid conditioning. Curr Opin Neurobiol 10:717-724. CrossRef Medline

Medina JF, Garcia KS, Mauk MD (2001) A mechanism for savings in the cerebellum. J Neurosci 21:4081-4089. Medline

Najafi F, Giovannucci A, Wang SSH, Medina JF (2014) Sensory-driven enhancement of calcium signals in individual Purkinje cell dendrites of awake mice. Cell Rep 6:792-798. CrossRef Medline

Neufeld M, Mintz M (2001) Involvement of the amygdala in classical conditioning of eyeblink response in the rat. Brain Res 889:112-117. CrossRef Medline

Paré WP, Glavin GB (1986) Restraint stress in biomedical research: a review. Neurosci Biobehav Rev 10:339-370. CrossRef Medline

Populin LC, Yin TC (1998) Behavioral studies of sound localization in the cat. J Neurosci 18:2147-2160. Medline

Sakamoto T, Endo S (2008) GABAA receptors in deep cerebellar nuclei play important roles in mouse eyeblink conditioning. Brain Res 1230:125-137. CrossRef Medline

Sakamoto T, Endo S (2010) Amygdala, deep cerebellar nuclei and red nucleus contribute to delay eyeblink conditioning in C57BL/6 mice. Eur J Neurosci 32:1537-1551. CrossRef Medline

Schmidt RA, Lee TD (2013) Motor learning and performance: from principles to application, Ed 5. Champaign, IL: Human Kinetics.

Schneiderman N, Fuentes I, Gormezano I (1962) Acquisition and extinction of the classically conditioned eyelid response in the albino rabbit. Science 136:650-652. CrossRef Medline

Schwarz C, Hentschke H, Butovas S, Haiss F, Stüttgen MC, Gerdjikov TV, Bergner CG, Waiblinger C (2010) The head-fixed behaving rat-procedures and pitfalls. Somatosens Mot Res 27:131-148. CrossRef Medline

Skelton RW (1988) Bilateral cerebellar lesions disrupt conditioned eyelid responses in unrestrained rats. Behav Neurosci 102:586-590. CrossRef Medline

Squire LR (1986) Mechanisms of memory. Science 232:1612-1619. CrossRef Medline

Vogel EH, Brandon SE, Wagner AR (2003) Stimulus representation in SOP. II. An application to inhibition of delay. Behav Processes 62:27-48. CrossRef Medline

Vogel RW, Ewers M, Ross C, Gould TJ, Woodruff-Pak DS (2002) Age-related impairment in the 250-millisecond delay eyeblink classical conditioning procedure in C57BL/6 mice. Learn Mem 9:321-336. CrossRef Medline

Wada N, Kishimoto Y, Watanabe D, Kano M, Hirano T, Funabiki K, Nakanishi S (2007) Conditioned eyeblink learning is formed and stored without cerebellar granule cell transmission. Proc Natl Acad Sci U S A 104: 16690-16695. CrossRef Medline

White N, Kehoe E, Choi J, Moore J (2000) Coefficients of variation in timing of the classically conditioned eyeblink in rabbits. Psychobiology 28:520-524.

Woodruff-Pak DS (2006) Stereological estimation of Purkinje neuron number in C57BL/6 mice and its relation to associative learning. Neuroscience 141:233-243. CrossRef Medline

Yeo CH, Hardiman MJ, Glickstein M (1985) Classical conditioning of the nictitating membrane response of the rabbit. I. Lesions of the cerebellar nuclei. Exp Brain Res 60:87-98. CrossRef Medline 